\title{
Experimental study: using the continuous wave Doppler spectrum technique to detect left atrial pressure
}

\author{
Haining Zheng ${ }^{1 \# \wedge}$, Yan Jin ${ }^{2 \#}$, Yuwei Fu ${ }^{1}$, Rui Zhao ${ }^{1}$, Xiaoqing Wang ${ }^{1}$, Chaoyang Wen ${ }^{1 \wedge}$ \\ ${ }^{1}$ Department of Ultrasound, Peking University International Hospital, Beijing, China; ${ }^{2}$ Department of Cardiology, Northern Theater General \\ Hospital of the Chinese People's Liberation Army, Shenyang, China \\ Contributions: (I) Conception and design: C Wen; (II) Administrative support: None; (III) Provision of study materials or patients: H Zheng, Y Fu, \\ R Zhao, X Wang; (IV) Collection and assembly of data: H Zheng, Y Jin, Y Fu; (V) Data analysis and interpretation: H Zheng, R Zhao, Y Jin; (VI) \\ Manuscript writing: All authors; (VII) Final approval of manuscript: All authors. \\ \#These authors contributed equally to this work. \\ Correspondence to: Dr. Chaoyang Wen. Department of Ultrasound, Peking University International Hospital, No. 1, Shengmingyuan Road, \\ Zhongguancun Life Science Park, Changping District, Beijing 102206, China. Email: wencypkuih@163.com.
}

Background: This study sought to investigate the accuracy of estimating left atrial pressure (LAP) using the continuous wave Doppler spectrum of mitral regurgitation.

Methods: Dog models of left atrial hypertension with mitral regurgitation were established with disposable biopsy forceps and the injection of melamine formaldehyde resin microsphere suspension. A total of 40 models of left atrial hypertension with different hemodynamic statuses were established by injecting either esmolol or dobutamine in which the spectrums of mitral regurgitation were clear and the regurgitation velocity exceeded $3.5 \mathrm{~m} / \mathrm{s}$. The continuous wave Doppler spectrums of mitral regurgitation were recorded and analyzed to estimate left atrial pressure $\left(\mathrm{LAP}_{\mathrm{ECHO}}\right)$. The mean left atrial pressure $\left(\mathrm{LAP}_{\mathrm{C}-\mathrm{MEAN}}\right)$, the isovolumic diastolic left atrial pressure $\left(\mathrm{LAP}_{\mathrm{C}-\mathrm{IVRT}}\right)$, the maximum left atrial pressure $\left(\mathrm{LAP}_{\mathrm{C}-\mathrm{MAX}}\right)$, and the minimum left atrial pressure $\left(\mathrm{LAP}_{\mathrm{C}-\mathrm{MIN}}\right)$ were also measured using the catheter method in the same cardiac cycle.

Results: The $\mathrm{LAP}_{\mathrm{ECHO}}$ (mean \pm standard deviation; $11.77 \pm 4.36 \mathrm{mmHg}$ ) was correlated with the $\mathrm{LAP}_{\mathrm{C}-\mathrm{MEAN}}$ $(11.51 \pm 4.77 \mathrm{mmHg} ; \mathrm{r}=0.887, \mathrm{P}=0.000)$, but the difference was not statistically significant $(\mathrm{P}=0.459)$. The $\mathrm{LAP}_{\mathrm{ECHO}}$ was correlated with the $\mathrm{LAP}_{\mathrm{C} \text {-IVRT }}(12.16 \pm 4.72 \mathrm{mmHg} ; \mathrm{r}=0.883, \mathrm{P}=0.000)$, but the difference was not statistically significant $(\mathrm{P}=0.271)$. There was a correlation between the $\mathrm{LAP}_{\mathrm{C}-\mathrm{MEAN}}$ and the $\mathrm{LAP}_{\mathrm{C}-\mathrm{IVRT}}$ $(\mathrm{r}=0.987, \mathrm{P}=0.000)$, and the difference was statistically significant $(\mathrm{P}=0.000)$.

Conclusions: This study suggests that the ultrasound evaluation of LAP correlates well with LAP measured using the gold standard catheter method, and is a simple, convenient, non-invasive method to quantitatively estimate LAP. This method is promising, but further large-scale animal experiments and clinical studies need to be conducted.

Keywords: Left atrial pressure (LAP); continuous wave Doppler spectrum; mitral regurgitation; left atrial pressure measured by ultrasound $\left(\mathrm{LAP}_{\mathrm{ECHO}}\right) ; \mathrm{LAP}_{\mathrm{C}}$

Submitted Oct 27, 2021. Accepted for publication Jan 13, 2022.

doi: 10.21037/atm-21-6913

View this article at: https://dx.doi.org/10.21037/atm-21-6913

^ ORCID: Haining Zheng, 0000-0002-8837-2727; Chaoyang Wen, 0000-0002-8659-0085. 


\section{Introduction}

Left atrial pressure (LAP) is an important hemodynamic parameter of cardiac function (1). At present, LAP is mainly measured using the catheter method, or pulmonary artery wedge pressure is measured rather than LAP. These methods are invasive, and cannot be routinely used in clinical practice. Currently, a variety of non-invasive methods for evaluating LAP, such as the "Doppler + sphygmomanometer" method have been explored. Due to their inaccuracy and complexity, these methods have not been used in clinical practice $(2,3)$.

In the study of the left ventricular relaxation time constant $(\tau)$, based on the Weiss exponential equation $\left(\mathrm{P}=\mathrm{e}^{-\mathrm{t} / \mathrm{B}}\right)$, the simplified Bernoulli equation $\left(\Delta \mathrm{P}=4 \mathrm{~V}^{2}\right)$, and $\mathrm{P}=\Delta \mathrm{P}+\mathrm{LAP}$, Bai (4-6) used mathematical methods to derive "binary linear equations", which can be used to calculate $\tau$, and have been verified by animal experiments (7). The equations have 2 variables; that is, $\tau$ and LAP. If $\tau$ is eliminated, LAP can be calculated. This method has some advantages. The first is simplicity. It only needs to measure the two intervals of the descending branch of the mitral regurgitation spectrum and substitute them into the above equations. The second is accuracy. The equations are derived from mathematical laws, no assumptions are used in the deduction process, thus, the integrity of the theory was preserved (7).

In this study, we created a Beagle dog model of acute mitral regurgitation combined with impaired diastolic function to increase the LAP, and then recorded a continuous wave Doppler spectrum of mitral regurgitation to calculate the LAP. The catheter method was used as the "gold standard" to measure LAP to verify the accuracy of this non-invasive ultrasound LAP measurement method.

We present the following article in accordance with the ARRIVE reporting checklist (available at https://atm. amegroups.com/article/view/10.21037/atm-21-6913/rc).

\section{Methods}

\section{Experimental animals}

All animal experiments were conducted in the Nongnong (Beijing) Life Science and Technology Company. Experiments were performed under a project license (No. 20180826-115) granted by ethics board of Animal Experimental Center of Nongnong (Beijing) Life Science and Technology Company, in compliance with institutional guidelines for the care and use of animals.

A protocol was prepared before the study without registration. 20 healthy beagle dogs were provided by Nongnong (Beijing) Biotechnology Co., Ltd., aged 2.0-3.6 years (2.8 \pm 0.7 years) with a body weight of $13.5-23.0 \mathrm{~kg}(18.2 \pm 2.7 \mathrm{~kg})$. There were 8 females and 12 males. The animals were kept in a constant temperature of $18-22{ }^{\circ} \mathrm{C}$ with free access to water and food in separate cages. Surgery was performed after 7 days of adaptive feeding. At the end of the procedure, a rapid intravenous injection of $10 \%$ potassium chloride at $0.5 \mathrm{~mL}$ per kilogram of the body weight was used to euthanize the dogs under anesthesia.

\section{Main reagents and instruments}

The Resona7 color Doppler ultrasound system was purchased from Shenzhen Mindray Biomedical Electronics Co., Ltd. (China). The phased array heart probe, probe frequency 2.5 MHz. MP160 type BIOPAC multi-lead physiological recorder was purchased from American BIOPAC company. An ACM608 animal ventilator was purchased from Beijing Aerospace Changfeng Co., Ltd. (China). A WZS-50F6 dual-channel micro-injection pump was purchased from Zhejiang Smith Medical Instrument Co., Ltd. (China). Intravascular catheters (5F, $\left.\mathrm{RH}^{*} 5 \mathrm{SP} 0061 \mathrm{M}\right)$ were purchased from Terumo Medical Products Co., Ltd of Japan. A A70N25A arterial sheath group and GA35183 guide wire were purchased from Japan Termao Medical Products Co., Ltd. Melamine formaldehyde resin microspheres (average particle size $51.7 \mu \mathrm{m})$ were purchased from Wuhan Huake Weike Technology Co., Ltd. (China). The configuration method for melamine microsphere suspension was as follow: an injection of $200 \mathrm{mg}$ of melamine microsphere, mixed with $100 \mathrm{~mL}$ of sodium chloride, shaken by ultrasonic shaker, and an injection of lidocaine hydrochloride $(5 \mathrm{~mL}: 0.1 \mathrm{mg})$ purchased from Shanghai Hefeng Pharmaceutical Co., Ltd. the company.

\section{Establishing an animal model of mitral regurgitation combined with increased LAP}

The Beagle dogs were fasted for 24 hours before surgery. They were anesthetized by an intravenous injection of Propofol (Sichuan Guorui Salt Industry Co., Ltd., China) $(20-40 \mathrm{mg} / \mathrm{kg})$, and the skin was prepared on the neck, chest, and inner limbs. The dogs were placed in the supine position on the operating table, the trachea was intubated, 
the animal ventilator was connected, and the dogs were kept warm (7). Electrocardiograms were attached to the upper and lower limbs with electrode pads (7). Venous access was established in the marginal ear vein and maintained with $0.9 \%$ sodium chloride via intravenous injection (1-2 drops/s). After anesthesia, the pressure measurement catheter was inserted into the left ventricle via the right femoral artery. The chest was opened with a middle line incision to expose the heart, after which the pericardium was cut, the pericardium hammock sewn, and the heart subsequently fixed. The pressure measuring catheter was inserted into the left atrium through the left atrial appendage, and the catheter was fixed with a purse. The left common carotid artery was dissected and the distal end of the left common carotid artery was ligated, followed by a puncture of the left common carotid artery with a $16 \mathrm{G}$ trocar. A guide wire was then inserted into the $7 \mathrm{~F}$ arterial sheath, followed by continuation using disposable biopsy forceps to make a mitral regurgitation model. Under ultrasound guidance: (I) the guide wire entered the left ventricle through the left common carotid artery, the arterial sheath was sent into the left ventricle along the guide wire, and the guide wire was then withdrawn; (II) the front end of the arterial sheath was sent to the mitral valve anterior valve tip when the mitral valve was open, the disposable sterile cystoscope biopsy forceps were delivered through the arterial sheath; (III) the biopsy forceps were opened when they reached the level of the tendon below the edge of the anterior leaflet of the mitral valve, and the tendon was clamped when the mitral valve was opened to cause the tendon to break; (IV) ultrasonic observation of light-medium reflux was defined as the successful establishment of the animal model; $(\mathrm{V})$ if unsuccessful, the above procedure was repeated until the model was successfully established, and the biopsy forceps were then withdrawn. The degree of mitral regurgitation was estimated by the Doppler color reflux area as follow: mild-a color reflux area accounting for $<20 \%$ of the left atrium area; moderate- a color reflux area accounting for $20-40 \%$ of the left atrium area; and severe-a color reflux area accounting for $>40 \%$ of the left atrium area. After the successful creation of the mitral regurgitation model, under the guidance of ultrasound, the arterial sheath was withdrawn into the aortic sinus, and the left common carotid sheath was moved to shift the front end into the left coronary sinus. Melamine formaldehyde resin microsphere suspension was slowly injected into the left coronary artery sinus with $2 \mathrm{~mL}$ of microsphere suspension each time, every 5-10 min, which led to increased left ventricular enddiastolic pressure (LVEDP). The left ventricular pressure (LVP) corresponding to the starting point of the QRS complex of the electrocardiogram represents the LVEDP, and the increase of LVEDP $\geq 5 \mathrm{mmHg}$ indicated the successful construction of acute ischemic left ventricular diastolic dysfunction $(7,8)$. To adjust the hemodynamic state of the LAP by different degrees, a pump injection of esmolol hydrochloride was used to reduce myocardial contractility, or a pump injection of dobutamine hydrochloride was used to improve myocardial contractility; hemodynamic stability was regarded as successful modeling. In the end, each dog adjusted two stable cardiac function states through drugs. A multi-lead physiological recorder was used to monitor the electrocardiogram (ECG), LVP, and LAP in real time.

\section{Continuous wave Doppler spectrum acquisition of mitral regurgitation}

Echocardiography was performed on the left atrial hypertension models of different hemodynamic states in which the spectrums of mitral regurgitation were clear, and the regurgitation velocity exceeded $3.5 \mathrm{~m} / \mathrm{s}$. The continuous wave Doppler spectrums of mitral regurgitation were saved. Because continuous wave Doppler has high velocity resolution, it can detect very high-speed blood flow.

The following acquisition method was used: echocardiographic examination, adjust the probe position and rotate the probe direction on the apical 4-chamber heart and apical left ventricular long-axis section, color Doppler display the continuous wave Doppler sampling lines parallel to the direction of the reflux beam, obtain the best mitral regurgitation spectrum, set the spectral Doppler scan speed to $200 \mathrm{~mm} / \mathrm{s}$, and store a continuous wave Doppler spectrum loop of mitral regurgitation (see Figure 1A). The physiological instrument simultaneously recorded and stored the electrocardiogram, LVP curve, and the left atrium pressure curve.

\section{Ultrasonic measurement of LAP and catheter measurement}

The ultrasonic measurement of LAP was calculated using the method described below.

\section{Formulas}

The following formulas were used:

$$
\tau=(\mathrm{t} 1-\mathrm{t} 2) / \ln ((\mathrm{LAP}+16) /(\mathrm{LAP}+4))
$$



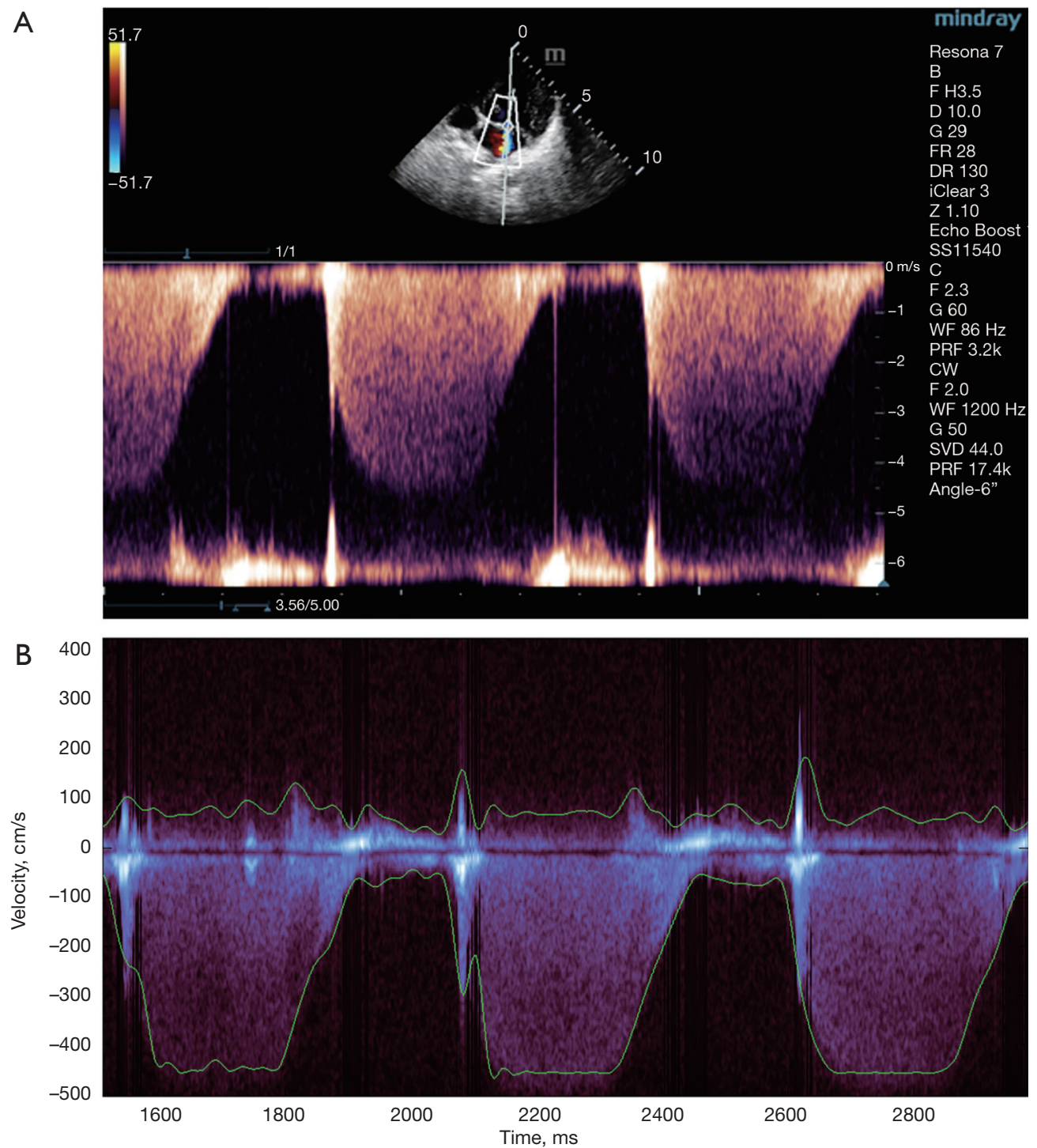

Figure 1 Continuous wave Doppler spectrum groove edge of mitral regurgitation. (A) Continuous wave Doppler spectrum of mitral regurgitation. (B) Automatic envelope of spectrum in "A" by software. FR, frame rate; DR, dynamic range; WF, wall filtering; SVD, sampling volume depth; PRF, pulse repetition frequency.

$$
\tau=(\mathrm{t} 1-\mathrm{t} 3) / \ln ((\mathrm{LAP}+36) /(\mathrm{LAP}+4))
$$

There are 2 variables, $\tau$ and LAP, in the formula. The durations of $t 1-t 2$ and $t 1-t 3$ of the descending branch of the continuous wave Doppler spectrum of mitral regurgitation were substituted, and the LAP was then calculated (5-7).

\section{t1-t 2 , and $\mathbf{t} \mathbf{1 - t} \mathbf{3}$ measurements}

The stored dynamic images of the mitral regurgitation continuous wave Doppler spectrums were analyzed using Mindray Company's patented software. To automatically identify the spectrum boundary, a smooth envelope was fitted and drawn (see Figure 1B); the software automatically determined the time values for $\mathrm{t} 1, \mathrm{t} 2$, and $\mathrm{t} 3$ of the velocity on the envelope line at 1,2 , and $3 \mathrm{~m} / \mathrm{s}$, and calculated the duration of $\mathrm{t} 1-\mathrm{t} 2$, and $\mathrm{t} 1-\mathrm{t} 3$ (7).

\section{LAP $_{\text {ECHO }}$ calculation}

The research group wrote the binary linear Eq. [1] and Eq. [2] (see above) into software, input $\mathrm{t} 1-\mathrm{t} 2, \mathrm{t} 1-\mathrm{t} 3$, which could automatically calculate $\mathrm{LAP}_{\mathrm{ECHO}}$. $\mathrm{LAP}_{\mathrm{ECHO}}$ was calculated for 3 consecutive cardiac cycles, and the average value was selected for the statistical analysis. The software 


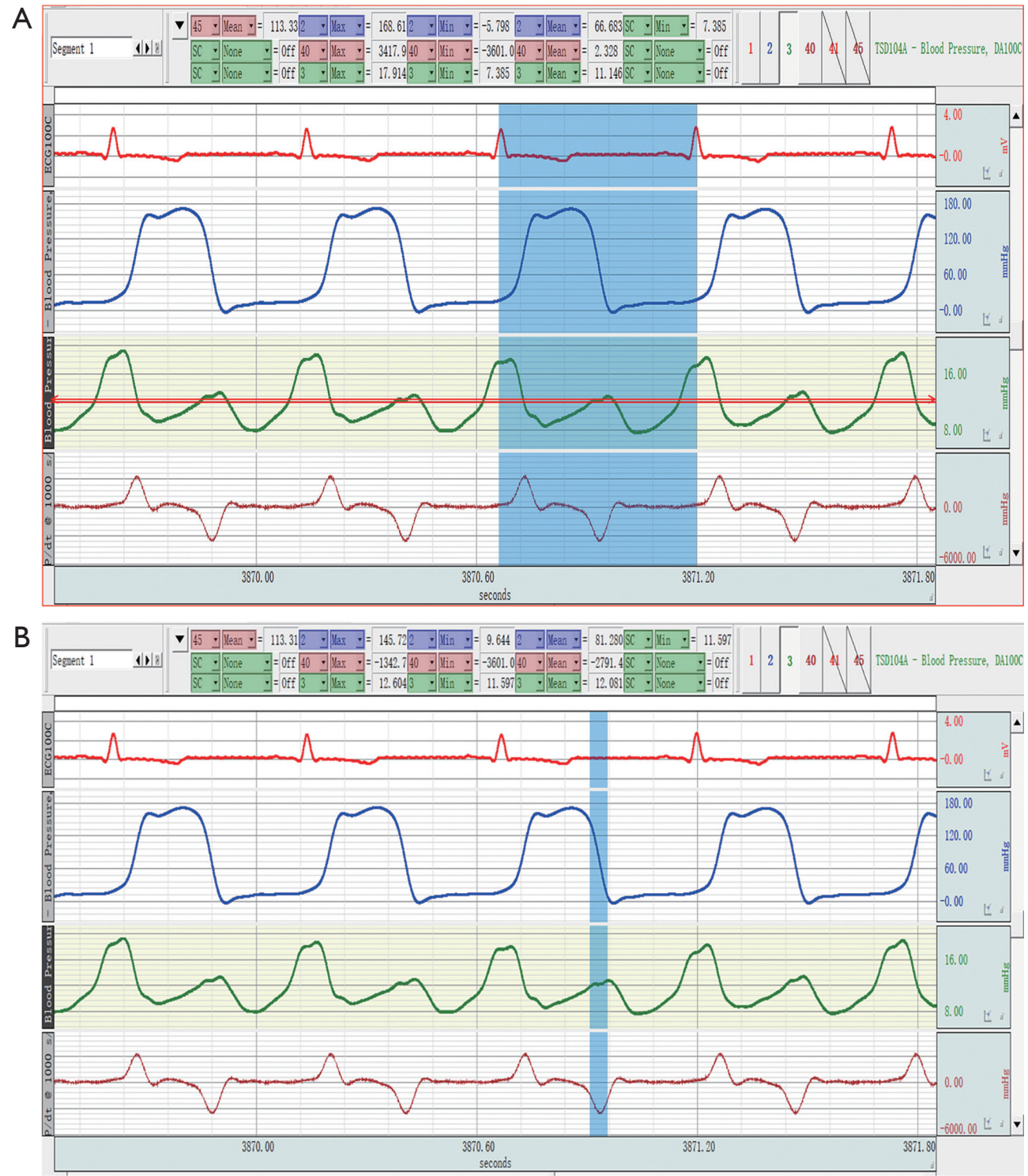

Figure 2 Physiological curve recorded by a polyconducting physiological recorder. From top to bottom: the ECG, LVP curve, LAP curve, left ventricular pressure $\mathrm{dP} / \mathrm{dt}$ curve. $\mathrm{LAP}_{\mathrm{C}-\mathrm{MAX}}: 17.914 \mathrm{mmHg} ; \mathrm{LAP}_{\mathrm{C}-\mathrm{MIN}}: 7.385 \mathrm{mmHg} ; \mathrm{LAP}_{\mathrm{C}-\mathrm{MEAN}}: 11.146 \mathrm{mmHg} \mathrm{LAP}_{\mathrm{C}-\mathrm{IVRT}}: 12.081$ mmHg. ECG, electrocardiogram; LAP, left atrial pressure; $\mathrm{LAP}_{\mathrm{C}-\mathrm{MAX}}$, the maximum left atrial pressure; $\mathrm{LAP}_{\mathrm{C}-\mathrm{MIN}}$, the minimum left atrial pressure; $\mathrm{LAP}_{\mathrm{C}-\mathrm{MEAN}}$, the mean left atrial pressure; $\mathrm{LAP}_{\mathrm{C}-\mathrm{IVRT}}$, the isovolumic diastolic left atrial pressure.

can be downloaded from: https://sourceforge.net/projects/ tauformula/files/.

The catheter measurement of the LAP $\left(\mathrm{LAP}_{\mathrm{C}}\right)$ adopts the data analysis software (AcqKnowledge4.2) of the multilead physiological recorder to directly measure the mean LAP $\left(\mathrm{LAP}_{\mathrm{C}-\mathrm{MEAN}}\right)$, isovolumic diastolic LAP (LAP $\left.\mathrm{L}_{\mathrm{CIVRT}}\right)$, maximum $\mathrm{LAP}\left(\mathrm{LAP}_{\mathrm{C}-\mathrm{MAX}}\right)$, and the minimum LAP ( $\left.\mathrm{LAP}_{\mathrm{C}-\mathrm{MIN}}\right)$ within a cardiac cycle (see Figure 2). The measurement method of LAP during isovolumic diastole (after the aortic valve closure and before the mitral valve opening) is to measure the average value of the $\mathrm{LAP}$, which is recorded as $\mathrm{LAP}_{\mathrm{C}}$ IVRT The $\mathrm{LAP}_{\mathrm{C}-\mathrm{MEAN}}$, and $\mathrm{LAP}_{\mathrm{C}-\mathrm{IVRT}}$, etc., were measured by catheterization within 3 consecutive cardiac cycles, and the average value was used for the statistical analysis.

\section{Statistical analysis}

SPSS 25.0 software was used for the statistical analysis. 


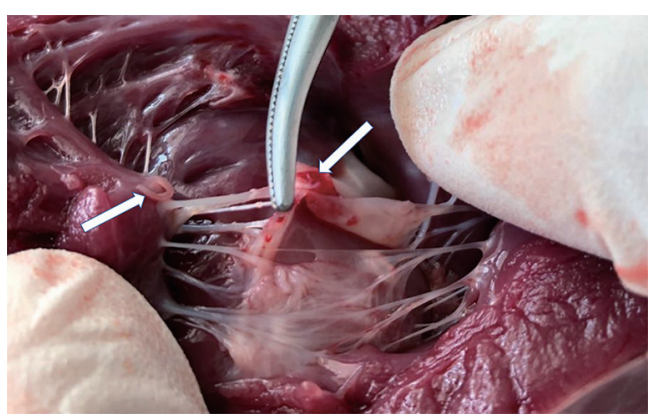

Figure 3 Mitral valve tendon rupture specimen. The two arrows indicate the two broken ends of the tendon cut by the biopsy forceps.

Table $1 \mathrm{LAP}$ measured by ultrasound and catheter $(\mathrm{mmHg})$

\begin{tabular}{lcc}
\hline Parameters $(n=40)$ & Ranges & Mean \pm SD \\
\hline LAP $_{\text {ECHO }}$ & $4.24-22.93$ & $11.77 \pm 4.36$ \\
LAP $_{\text {C-MEAN }}$ & $3.68-22.87$ & $11.51 \pm 4.77$ \\
LAP $_{\text {C-IVRT }}$ & $3.94-23.54$ & $12.16 \pm 4.72$ \\
LAP $_{\text {C-MAX }}$ & $8.94-25.30$ & $15.70 \pm 4.36$ \\
LA $_{\text {PC-MIN }}$ & $1.57-20.81$ & $8.33 \pm 4.33$ \\
\hline
\end{tabular}

$\mathrm{LAP}$, left atrial pressure; $\mathrm{LAP}_{\mathrm{ECHO}}$, left atrial pressure measured by ultrasound; $L_{\text {AP }} \mathrm{P}_{\mathrm{C} \text { MEAN }}$, the mean left atrial pressure; $\mathrm{LAP}_{\mathrm{C}-\mathrm{IVRT}}$, the isovolumic diastolic left atrial pressure; $\mathrm{LAP}_{\mathrm{C}-\mathrm{MAX}}$, the maximum left atrial pressure; $L A P_{C-M I N}$, the minimum left atrial pressure.

The measurement data are expressed as mean \pm standard deviation (SD), and the relationship between the $\mathrm{LAP}_{\mathrm{C}}$ and $\mathrm{LAP}_{\mathrm{ECHO}}$ was assessed by a Pearson correlation analysis. The student's $t$-test was used to compare the difference between 2 values. A $\mathrm{P}$ value $<0.05$ was considered statistically significant.

\section{Results}

\section{Animal model construction}

The Beagle model of mitral regurgitation was successfully established (see Figure 3). After the mitral regurgitation model was successfully established, $2 \mathrm{~mL}$ of melamine formaldehyde resin microsphere suspension was injected into the left aortic sinus at a rate of $5 \mathrm{~mL} / 20 \mathrm{~s}$ every 5 10 minutes. The LVEDP was increased by $>5 \mathrm{mmHg}$ (with an average increase of $17 \mathrm{mmHg}$ ), which represented the successful establishment of the acute ischemic left ventricular diastolic dysfunction model. This process took about 90 minutes. After 20 minutes of continuous observation, 40 models of left atrial hypertension with different hemodynamic states were established by injecting either esmolol or dobutamine.

\section{LAP measured by ultrasound and catheter}

Table 1 shows the LAP measured by ultrasound ( $\left.\mathrm{LAP}_{\mathrm{ECHO}}\right)$, mean left atrial pressure $\left(\mathrm{LAP}_{\mathrm{C}-\mathrm{MEAN}}\right)$, isovolumic diastolic left atrial pressure $\left(\mathrm{LAP}_{\mathrm{C}-\mathrm{IVRT}}\right)$, maximum left atrial pressure $\left(\mathrm{LAP}_{\mathrm{C}-\mathrm{MAX}}\right)$, and minimum left atrial pressure $\left(\mathrm{LAP}_{\mathrm{C}-\mathrm{MIN}}\right)$.

\section{Relationship between the $L A P_{E C H O}$ and $L A P_{C-M E A N}$}

In this study, the mitral regurgitation spectrum was taken 3 times using the formula described above. $t 1, t 2$, and $t 3$ occurred in the isovolumic diastolic phase of the cardiac physiological cycle. Thus, the LAP calculated by ultrasound corresponded to $\mathrm{LAP}_{\text {C-IVRT }}$. Clinically, the average LAP is often used as a parameter to determine the size of the LAP. Thus, the correlations among the $\mathrm{LAP}_{\mathrm{ECHO}}, \mathrm{LAP}_{\mathrm{C}-}$ IVRTT, and $\mathrm{LAP}_{\mathrm{C}-\mathrm{MEAN}}$ were analyzed separately. The $\mathrm{LAP}_{\mathrm{C}-}$ MEAN, which is the "gold standard", was selected to verify the accuracy of the $\mathrm{LAP}_{\mathrm{ECHO}}$. The $\mathrm{LAP}_{\mathrm{ECHO}}$ was between $4.24-22.93(11.77 \pm 4.36) \mathrm{mmHg}$, and the $\mathrm{LAP}_{\mathrm{C}-\mathrm{MEAN}}$ was between $3.68-22.87(11.51 \pm 4.77) \mathrm{mmHg}$; there was no statistically significant difference between the 2 groups $(\mathrm{P}=0.459)$. The correlation between the $\mathrm{LAP}_{\mathrm{C}-\mathrm{MEAN}}$ and $\mathrm{LAP}_{\mathrm{ECHO}}$ was statistically significant $(\mathrm{r}=0.887, \mathrm{P}=0.000$; see Figure 4). In relation to the Bland-Altman method analysis, the average value of the difference between 40 cases of the $\mathrm{LAP}_{\mathrm{C} \text {-MEAN }}$ and $\mathrm{LAP}_{\mathrm{ECHO}}$ paired data was $\overline{\mathrm{d}}=-0.26$, the $\mathrm{SD}$ of the difference was 2.21 , and the $95 \%$ consistency limit was $\overline{\mathrm{d}} \pm 1.96 \mathrm{SD}=-0.26 \pm 1.96 \times 2.21$; that is $(-4.60,4.07)$. The $2.5 \%(1 / 40)$ point was outside the $95 \%$ consistency limit, indicating that the 2 methods were consistent (see Figure 5).

\section{Relationship between the $L A P_{E C H O}$ and $L A P_{C-I V R T}$}

The $\mathrm{LAP}_{\mathrm{ECHO}}$ measured by the ultrasound method was between 4.24-22.93 $(11.77 \pm 4.36) \mathrm{mmHg}$, and the $\mathrm{LAP}_{\text {C-IVRTS }}$ measured by the catheter method was between 3.94-23.54 $(12.16 \pm 4.72) \mathrm{mmHg}$; the difference between the 2 groups was not statistically significant $(\mathrm{P}=0.271)$.

The correlation between the $\mathrm{LAP}_{\mathrm{C}-\mathrm{IVRT}}$ and $\mathrm{LAP}_{\mathrm{ECHO}}$ was statistically significant $(\mathrm{r}=0.883, \mathrm{P}=0.000$; see Figure 6). In relation to the Bland-Altman method analysis, the average value of the difference between the 40 cases of LAP $_{\text {C-IVRT }}$ and 


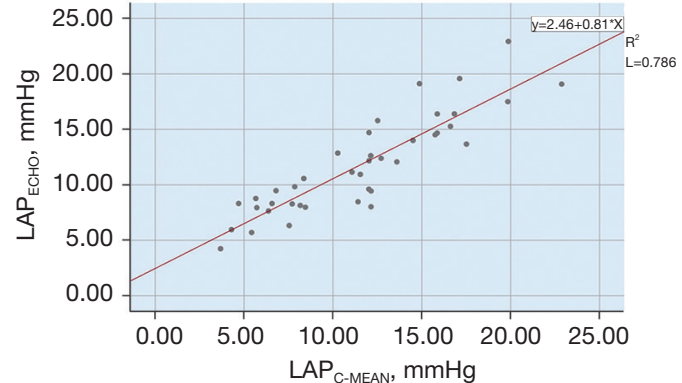

Figure 4 The correlation between the $\mathrm{LAP}_{\mathrm{ECHO}}$ and $\mathrm{LAP}_{\mathrm{C}-\mathrm{MEAN}}$. LAP, left atrial pressure; $\mathrm{LAP}_{\mathrm{ECHO}}$, left atrial pressure measured by ultrasound; $\mathrm{LAP}_{\mathrm{C}-\mathrm{MEAN}}$, the mean left atrial pressure.

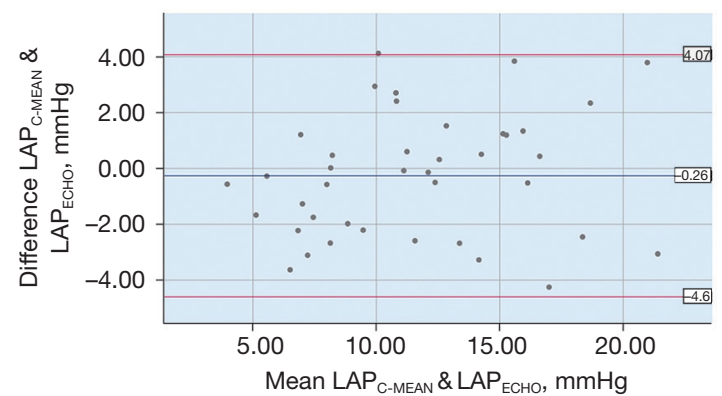

Figure 5 The relationship between the $\mathrm{LAP}_{\mathrm{ECHO}}$ and $\mathrm{LAP}_{\mathrm{C}-\mathrm{MEAN}}$ using the Bland-Altman method. The abscissa is the average of the $\mathrm{LAP}_{\mathrm{ECHO}}$ and $\mathrm{LAP}_{\mathrm{C}-\mathrm{MEAN}}$, the difference between the ordinates; the blue line is the average of the difference between the $\mathrm{LAP}_{\mathrm{ECHO}}$ and $\operatorname{LAP}_{\text {C-MEAN }}(\overline{\mathrm{d}})$; the red line is $(\overline{\mathrm{d}} \pm 1.96 \mathrm{SD})$. LAP, left atrial pressure; $\mathrm{LAP}_{\mathrm{ECHO}}$, left atrial pressure measured by ultrasound; $\mathrm{LAP}_{\mathrm{C}-\mathrm{MEAN}}$, the mean left atrial pressure.

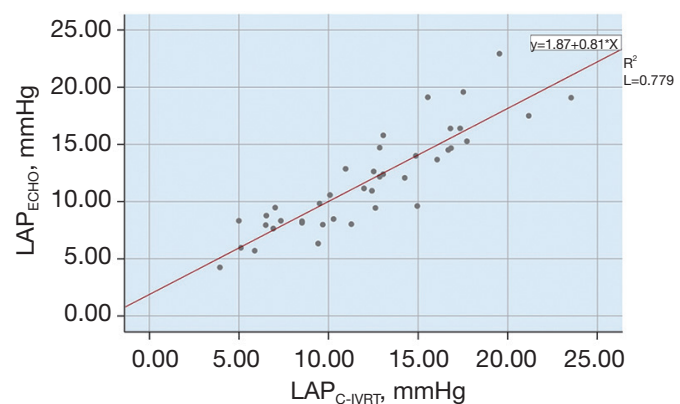

Figure 6 The correlation between the $\mathrm{LAP}_{\mathrm{ECHO}}$ and $\mathrm{LAP}_{\mathrm{C}-\mathrm{IVRT}}$. $\mathrm{LAP}_{\mathrm{ECHO}}$, left atrial pressure measured by ultrasound; LAP $\mathrm{C}_{\mathrm{C}-\mathrm{IVRT}}$, the isovolumic diastolic left atrial pressure.

$\mathrm{LAP}_{\mathrm{ECHO}}$ paired data was $\overline{\mathrm{d}}=0.39$, the $\mathrm{SD}$ of the difference was 2.23 , and the $95 \%$ consistency limit was $\bar{d} \pm 1.96 \mathrm{SD}$ $=0.39 \pm 1.96 \times 2.23$; that is, $(-3.98,4.76)$. The $5 \%(2 / 40)$ point

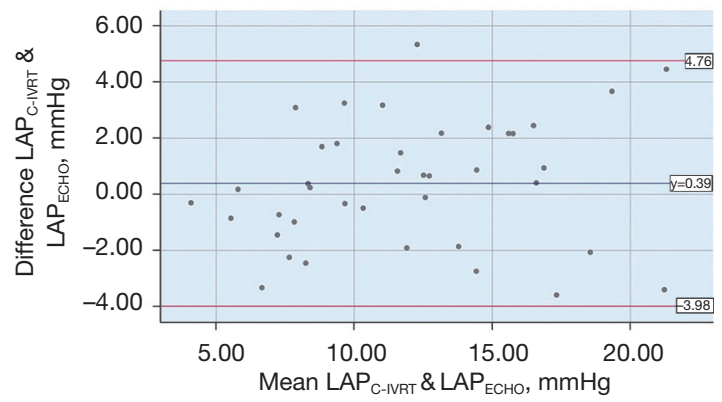

Figure 7 The relationship between the $\mathrm{LAP}_{\mathrm{ECHO}}$ and $\mathrm{LAP}_{\mathrm{C} \text {-IVRT }}$ using the Bland-Altman method. The abscissa is the average of the $\mathrm{LAP}_{\mathrm{ECHO}}$ and $\mathrm{LAP}_{\mathrm{C}-\mathrm{IVRT}}$, the difference between the ordinates; the blue line is the average of the difference between the $\mathrm{LAP}_{\mathrm{ECHO}}$ and $\operatorname{LAP}_{\text {C-IVRT }}(\overline{\mathrm{d}})$; the red line is $(\overline{\mathrm{d}} \pm 1.96 \mathrm{SD})$. $\mathrm{LAP}_{\mathrm{ECHO}}$, left atrial pressure measured by ultrasound; $\mathrm{LAP}_{\mathrm{C}-\mathrm{IVRT}}$, the isovolumic diastolic left atrial pressure.

was outside the $95 \%$ consistency limit, and the 2 methods were considered to have good consistency (see Figure 7).

\section{The relationship between the $L A P_{C-M E A N}$ and $L A P_{C-I V R T}$}

In clinical practice, the average LAP is usually used as an indicator for evaluating cardiac function. The LAP calculated by the formula in this study corresponded to the isovolumic diastolic LAP. The $\mathrm{LAP}_{\mathrm{C}-\mathrm{MEAN}}$ was between 3.68-22.87 (11.51 \pm 4.77$) \mathrm{mmHg}$, the $\mathrm{LAP}_{\mathrm{C}-\mathrm{IVRT}}$ was between 3.94-23.54 (12.16 \pm 4.72$) \mathrm{mmHg}$, and the difference was statistically significant $(\mathrm{P}=0.000)$. The analysis between the $\mathrm{LAP}_{\mathrm{C}-\mathrm{MEAN}}$ and $\mathrm{LAP}_{\mathrm{C}-\mathrm{IVRT}}$ showed a significant correlation $(\mathrm{r}=0.987, \mathrm{P}=0.000$; see Figure 8$)$. In relation to the BlandAltman method analysis, the average value of the difference between the paired data of the $\mathrm{LAP}_{\mathrm{C}-\mathrm{MEAN}}$ and $\mathrm{LAP}_{\mathrm{C}-\mathrm{IVRT}}$ was $\bar{d}=-0.65$, the SD of the difference was 0.76 , and the $95 \%$ consistency limit $(\mathrm{d} \pm 1.96 \mathrm{SD})$ was $-0.65 \pm 1.96 \times 0.76$; that is, $(-2.14,0.83)$. The $10 \%(4 / 40)$ point was outside the $95 \%$ consistency limit, and the consistency between the 2 methods was considered good (see Figure 9).

\section{Discussion}

Following the wide application of ultrasound technology in clinical settings, some scholars have studied the method of using ultrasound technology to evaluate the LAP. "Doppler + sphygmomanometer" is the most commonly used method to study the LAP. In patients with mitral 


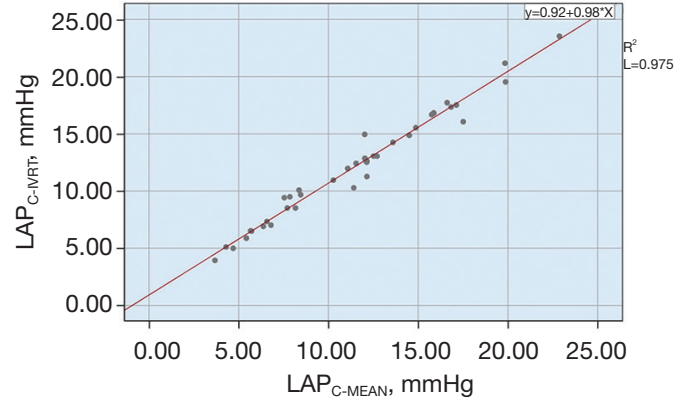

Figure 8 The correlation between the $\mathrm{LAP}_{\mathrm{C}-\mathrm{MEAN}}$ and LAP $\mathrm{C}_{\mathrm{C}-\mathrm{IVRT}}$. $\mathrm{LAP}_{\mathrm{C}-\mathrm{MEAN}}$, the mean left atrial pressure; $\mathrm{LAP}_{\mathrm{C} \text {-IVRT}}$, the isovolumic diastolic left atrial pressure.

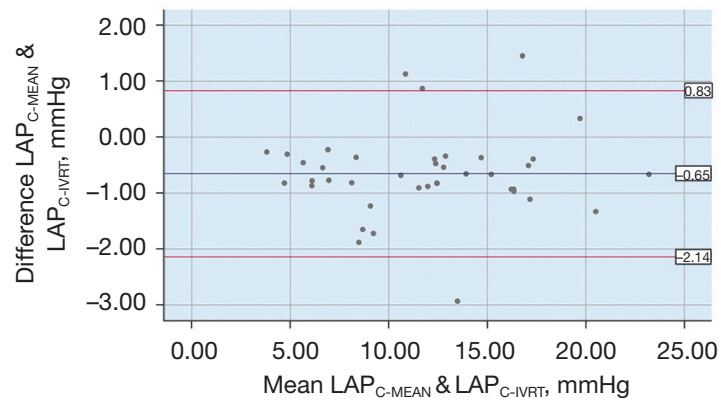

Figure 9 The relationship between the $\mathrm{LAP}_{\mathrm{C}-\mathrm{MEAN}}$ and $\mathrm{LAP}_{\mathrm{C}-\mathrm{IVRT}}$ using the Bland-Altman method. The abscissa is the average of the $\mathrm{LAP}_{\mathrm{C}-\mathrm{MEAN}}$ and $\mathrm{LAP}_{\mathrm{C}-\mathrm{IVRT}}$, the difference between the ordinates; the blue line is the average of the difference between $\mathrm{LAP}_{\mathrm{C}-M E A N}$ and $\operatorname{LAP}_{\text {C-IVRT }}(\overline{\mathrm{d}})$; the red line is $(\overline{\mathrm{d}} \pm 1.96 \mathrm{SD}) . \mathrm{LAP}_{\mathrm{C}-\mathrm{MEAN}}$, the mean left atrial pressure; $\mathrm{LAP}_{\mathrm{C}-\mathrm{IVRT}}$, the isovolumic diastolic left atrial pressure.

regurgitation, the maximum transvalvular pressure difference $(\Delta \mathrm{P})$ of mitral regurgitation is the difference between left ventricular systolic pressure $(\mathrm{P})$ and LAP; thus, the LAP can be calculated as $\mathrm{P}$ minus mitral regurgitation pressure difference; that is, $\mathrm{LAP}=\mathrm{P}-\Delta \mathrm{P}$. In patients without left ventricular outflow tract stenosis, $\mathrm{P}$ is similar to brachial artery systolic pressure, and can be measured with a sphygmomanometer. The peak velocity of mitral regurgitation measured by continuous Doppler spectrum can be calculated automatically using the following formula: $\Delta \mathrm{P}=4 \mathrm{~V}^{2}(3)$. However, using the cuff method, measurement errors of brachial artery systolic pressure are common, especially when there is calcification in the brachial artery. This affects the accuracy of LAP measurements.

In the 20th century, many scholars systematically observed and studied the relationship between pulmonary vein blood flow and LAP $(9,10)$, and found that patients with high LAP changed from the systolic pulmonary vein blood flow spectrum to diastolic pulmonary vein blood flow spectrum. Such qualitative evaluation studies cannot measure LAP quantitatively. There are many types of pulmonary vein blood flow spectrums. The spectrum types are easily affected by LAP, left ventricular systolic function, diastolic function, heart rate, age, etc., which affect the accuracy and effectiveness of ultrasound evaluations of LAP. In addition, it is sometimes difficult to collect negative phase waves of atrial contraction by transthoracic ultrasound.

Some scholars have explored the use of mitral valve positive flow spectrum to evaluate LAP, suggesting that there is a certain correlation between them (11). However, the accuracy of this method is poor due to factors such as left ventricular relaxation, ventricular compliance, left ventricular preload, ventricular interaction, pericardial limitation, and left atrial function (12).

Tissue Doppler imaging can quantify myocardial wall motion amplitude, early diastolic mitral annulus tissue Doppler velocity $\left(E^{\prime}\right)$, and the left ventricular relaxation time constant $(\tau)$. Some scholars have used the ratio of early diastolic mitral flow velocity (E) to early diastolic mitral annular tissue Doppler velocity (E/E') to evaluate LAP. The calculation formula of LAP is $\mathrm{LAP}=1.24 \times\left(\mathrm{E} / \mathrm{e}^{\prime}\right)+1.9(12)$. However, relevant research results differ, and some scholars believe that it has only a moderate correlation compared to the catheter method, while other scholars say that the correlation is poor or there is no correlation (13-15).

Bai derived a novel method to measure LAP by continuous wave Doppler spectrum $(7,16)$. This method measures the blood flow velocity at 1,2 , and $3 \mathrm{~m} / \mathrm{s}$ at times $\mathrm{t} 1, \mathrm{t} 2$, and $\mathrm{t} 3$ at the descending branch of the mitral regurgitation curve, calculates the duration of $\mathrm{t} 1-\mathrm{t} 2$, and $\mathrm{t} 1-$ $\mathrm{t} 3$, and then estimates the LAP. In the process of formula derivation, 3 points $(\mathrm{t} 1,1 \mathrm{~m} / \mathrm{s}),(\mathrm{t} 2,2 \mathrm{~m} / \mathrm{s}),(\mathrm{t} 3,3 \mathrm{~m} / \mathrm{s})$ were selected for the calculation. This method of taking integers is convenient for the calculation; the 3 points are always taken in the isovolumic relaxation phase (6).

LAP is composed of systolic and diastolic phases, and in the clinic, average pressure is usually used. There was a significant difference between the $\mathrm{LAP}_{\mathrm{C}-\mathrm{MEAN}}$ and $\mathrm{LAP}_{\mathrm{C}-\mathrm{IVRT}}$. The isovolumic diastolic phase was closed after the aortic valve was closed, but before the mitral valve was opened; the isovolumic diastolic phase LAP curve was relatively straight, located in the ascending branch of the $\mathrm{v}$ wave, close to the $\mathrm{v}$ wave peak, and higher than the average pressure of the left 
atrium. There were obvious differences between the $\mathrm{LAP}_{\mathrm{C}}$ MEAN and $\mathrm{LAP}_{\mathrm{C}-\mathrm{IVRT}}$, and the $\mathrm{LAP}_{\text {IVRT }}$ was slightly larger than the LAP $\mathrm{C}_{\mathrm{C} \text { MEAN }}$.

In this study, we used animal experiments to verify a new method for noninvasive quantitative measurement of LAP. The method was non-invasive and simple, and had a good correlation with catheter measurements. The method does not require systolic blood pressure measurements, but only needs a clear continuous Doppler spectrum of mitral regurgitation. Based on current advances in computer and software technology, if the ultrasound system is slightly modified and the relevant software of the method is implemented, ( $\mathrm{t} 1-\mathrm{t} 2)$ and $(\mathrm{t} 1-\mathrm{t} 3)$ can be automatically measured, and the LAP can be calculated to achieve "1 key" to "measure" LAP. Continuous wave Doppler is commonly used in echocardiography. If this method can be verified by animal experiments and large-cohort clinical trials, it will enable the real-time quantitative measurement of LAP during conventional echocardiography and has epoch-making significance for the accurate diagnosis and treatment of heart diseases (8).

\section{Limitations}

Our study had some limitations. First, the study was an animal study with a small sample size, and only an animal model of acute mitral regurgitation combined with increased LAP was used. The calculation still needs to be verified by large-cohort clinical trials. Second, this method is only applicable when there is mitral regurgitation, and the spectrums of mitral regurgitation should be clear and the regurgitation velocity should exceed $3.5 \mathrm{~m} / \mathrm{s}$. Third, when collecting the continuous Doppler spectrum of mitral regurgitation, the position and angle of the probe must be adjusted to ensure that the Doppler sampling lines are parallel and pass through the regurgitation beam in each plane, which is highly dependent on the operator. In addition, a clear mitral regurgitation spectrum must be collected to accurately measure $\mathrm{t} 1, \mathrm{t} 2$, and $\mathrm{t} 3$, and to accurately measure LAP.

\section{Conclusions}

This study showed the good correlation between the $\mathrm{LAP}_{\mathrm{ECHO}}$ and $\mathrm{LAP}_{\mathrm{C}}$. Further, the new method for detecting LAP by continuous wave Doppler spectrum is simple, convenient, non-invasive, and can be used to quantitatively estimate LAP, which is promising. Further large-scale animal experiments and clinical studies need to be conducted.

\section{Acknowledgments}

The authors would sincerely like to thank Xu-Fang Bai (Institute of Cardiology, University of Ottawa, Canada) for his formula for calculating LAP. The authors would also like to express their appreciation to those at Mindray Medical International Limited, especially Dr. Yong-Qiang Dong, for their tremendous help. Without this collaboration, our clinicians would not have been able to achieve the accurate measurement of the Doppler spectrum. Additionally, the authors would like to thank Michael Chen (Telus Mobility, Canada) for his development of the equation group resolving software, which was very helpful.

Funding: This work was supported by the National Natural Science Foundation of China (No. 81771833) and the Natural Science Foundation of Beijing, China (No. 7172209).

\section{Footnote}

Reporting Checklist: The authors have completed the ARRIVE reporting checklist. Available at https://atm. amegroups.com/article/view/10.21037/atm-21-6913/rc

Data Sharing Statement: Available at https://atm.amegroups. com/article/view/10.21037/atm-21-6913/dss

Conflicts of Interest: All authors have completed the ICMJE uniform disclosure form (available at https://atm. amegroups.com/article/view/10.21037/atm-21-6913/ coif). All authors report that this work was supported by the National Natural Science Foundation of China (No. 81771833) and the Natural Science Foundation of Beijing, China (No. 7172209), and received technical support from Mindray Medical International Limited and Michael Chen (Telus Mobility, Canada). The authors have no other conflicts of interest to declare.

Etbical Statement: The authors are accountable for all aspects of the work in ensuring that questions related to the accuracy or integrity of any part of the work are appropriately investigated and resolved. Animal experiments were performed under a project license (No. 20180826115) granted by ethics board of Animal Experimental Center of Nongnong (Beijing) Life Science and Technology 
Company, in compliance with institutional guidelines for the care and use of animals.

Open Access Statement: This is an Open Access article distributed in accordance with the Creative Commons Attribution-NonCommercial-NoDerivs 4.0 International License (CC BY-NC-ND 4.0), which permits the noncommercial replication and distribution of the article with the strict proviso that no changes or edits are made and the original work is properly cited (including links to both the formal publication through the relevant DOI and the license). See: https://creativecommons.org/licenses/by-nc-nd/4.0/.

\section{References}

1. Thomas L, Abhayaratna WP. Left Atrial Reverse Remodeling: Mechanisms, Evaluation, and Clinical Significance. JACC Cardiovasc Imaging 2017;10:65-77.

2. Zhu N, Chen $H$, Zhao $X$, et al. Left atrial diameter in heart failure with left ventricular preserved, mid-range, and reduced ejection fraction. Medicine (Baltimore) 2019;98:e18146.

3. Pressman GS, Ranjan R, Olex S. A simple technique for bedside estimation of left atrial pressure. Echocardiography 2019;36:1972-8.

4. Bai XF, Ma AX. Symmetry of cardiac function assessment. J Geriatr Cardiol 2016;13:517-20.

5. Bai X, Wang Q. Time constants of cardiac function and their calculations. Open Cardiovasc Med J 2010;4:168-72.

6. Bai X. Calculation of left ventricular relaxation time constant-Tau in humans by continuous-wave Doppler. Open Cardiovasc Med J 2008;2:9-11.

7. Wen C, Sun J, Fan C, et al. Calculation of Left Ventricular Diastolic Time Constant (TAU) in Dogs with Mitral Regurgitation Using Continuous-Wave Doppler. Ultrasound Med Biol 2018;44:1778-85.

8. Pathan F, D'Elia N, Nolan MT, et al. Normal Ranges of

Cite this article as: Zheng $\mathrm{H}$, Jin $\mathrm{Y}, \mathrm{Fu} \mathrm{Y}$, Zhao R, Wang X, Wen C. Experimental study: using the continuous wave Doppler spectrum technique to detect left atrial pressure. Ann Transl Med 2022;10(2):105. doi: 10.21037/atm-21-6913
Left Atrial Strain by Speckle-Tracking Echocardiography: A Systematic Review and Meta-Analysis. J Am Soc Echocardiogr 2017;30:59-70.e8.

9. Smallhorn JF, Freedom RM, Olley PM. Pulsed Doppler echocardiographic assessment of extraparenchymal pulmonary vein flow. J Am Coll Cardiol 1987;9:573-9.

10. Kuecherer HF, Muhiudeen IA, Kusumoto FM, et al. Estimation of mean left atrial pressure from transesophageal pulsed Doppler echocardiography of pulmonary venous flow. Circulation 1990;82:1127-39.

11. Choong CY, Abascal VM, Thomas JD, et al. Combined influence of ventricular loading and relaxation on the transmitral flow velocity profile in dogs measured by Doppler echocardiography. Circulation 1988;78:672-83.

12. Nagueh SF, Middleton KJ, Kopelen HA, et al. Doppler tissue imaging: a noninvasive technique for evaluation of left ventricular relaxation and estimation of filling pressures. J Am Coll Cardiol 1997;30:1527-33.

13. Cowie B, Kluger R, Rex S, et al. Noninvasive estimation of left atrial pressure with transesophageal echocardiography. Ann Card Anaesth 2015;18:312-6.

14. Geske JB, Sorajja P, Nishimura RA, et al. Evaluation of left ventricular filling pressures by Doppler echocardiography in patients with hypertrophic cardiomyopathy: correlation with direct left atrial pressure measurement at cardiac catheterization. Circulation 2007;116:2702-8.

15. Ommen SR, Nishimura RA, Appleton CP, et al. Clinical utility of Doppler echocardiography and tissue Doppler imaging in the estimation of left ventricular filling pressures: A comparative simultaneous Dopplercatheterization study. Circulation 2000;102:1788-94.

16. Beltrami M, Palazzuoli A, Padeletti L, et al. The importance of integrated left atrial evaluation: From hypertension to heart failure with preserved ejection fraction. Int J Clin Pract 2018. doi:10.1111/ijcp.13050.

(English Language Editor: L. Huleatt) 